\title{
ОБЩЕСТВЕННЫЙ АИААОГ
}

\author{
Болтаевский А.А., ПряАко И.П.
}

\section{РЕФОРМА РОССИЙСКОЙ ВЫСШЕЙ ШКОАЫ В ОЦЕНКАХ УЧАЩИХСЯ И ОБУЧАЮЩИХ: ОПЫТ ИССАЕАОВАНИЯ}

\begin{abstract}
Аннотация. В работе предложена оценка реформ российской высшей школы, направленных на ее поэтапное встраивание в Болонский прочесс, осуществляемый в нашей стране с 2003 г. Многие эксперты отмечают оторванность отечественных вузов от решения практических задач, заметное отставание российской образовательной системы от западной в подготовке специалистов в области прикладных наук. Насколько это соответствует действительности и насколько готовы студенчество и профессорско-преподавательский состав высшей школы России к новым возможностям станет предметом изучения в данной статье. Анализируются результаты экспресс-опроса, проведенного авторами настоящей статьи среди студентов и профессорско-преподавательского состава. Среди факторов, вызывающих настороженность со стороны российских экспертов, называется низкий уровень знания о иелях реформы и неосведомленность относительно мер по улучшению системы высшей школы. В статье подчеркивается, что основной целью обучения по Болонским стандартам сегодня видится создание единого интеллектуального пространства. Но, как показал проведенный авторами опрос, преплтствием к достижению заявленной иели вступают два фактора: низкий уровень владения студентами иностранными языками и недостаточный размер доходов. Указанное обстоятельство делает практически невозможным обучение большинства российских студентов за рубежом и снижает конкурентоспособность выпускников российских вузов с точки зрения потенциальньх работодателей по всему европейскому пространству.
\end{abstract}

Кнючевье слова: Образование, Болонский проиесс, университеты, компетентностный подход, образовательные стандарты, фундаментальные разработки, сочиальный институт, воспитание, обучение, научно-исследовательский поиск.

Review. The paper suggests the evaluation of the reforms of Russian higher schools aimed at its gradual integration into the Bologna process that has been conducted in our country since 2003. Many experts notice the divorcement of Russian universities from the solution of practical tasks, visible weakness of Russian educational system compared to the Western one when it comes to the preparation of professionals in the field of applied sciences. The subject of the article is the question whether it is true and to which extent the students and teaching staff of Russian higher schools are ready for the new opportunities. The article analyses the results of an express survey conducted by the authors among the 
students and the teaching stuff. Among the factors that cause vigilance in Russian experts are the low level of knowledge regarding the aims of the reform and lack of information about the measures to improve the system of higher education. It is highlighted in the article that the main goal of studying according to the Bologna standards nowadays is the creation of united intellectual space. But as the conducted survey has shown, there are two factors that block the fulfilment of this goal: low level of foreign language skills by the students and insufficient income. These circumstances make it practically impossible for the majority of Russian students to study abroad and decreases the competitiveness of the graduates of Russian universities from the point of view of potential employers all over Europe.

Keywords: education, Bologna process, universities, competence-based approach, educational standards, fundamental projects, social institute, upbringing, teaching, scientific research.

P еформа российской высшей школы в качестве своих главных целей провозгласила поворот образовательных учреждений к практике, максимальное приближение учебных программ к профессиональной деятельности будущих специалистов. При этом ведущие вузы страны на фоне происходящих перемен все шире вовлекаются в научно-исслеАовательский поиск, преАполагающий внеАрение научных инноваций в профессиональную среду (характерным примером явмяется организация научно-исскедовательских университетов). Хорошо известно, что зарожАение инновационной идеи и возможность использования новых научных результатов происходят на уровне как фундаментальных, так и поисковых исследований. Эти исследования ведутся теперь и в образовательных учреждениях. Высшая школа, вместе с тем, не Аолжна подменять собой произвоАство.

Процесс освоения и созАания новой техники, введения инноваций в начинается в стенах вуза с изысканий на фундаментально-теоретическом уровне. Аля последнего необходимо созАать условия в национальных исследовательских центрах. В чем видится отправная точка Аанных реформ?

В работах, посвященных современному образованию, рисуется идеац - университет как место, гАе в научном поиске на равных участвуют сообщество преподавателей и учащиеся. Инструментом поиска выступает интенсивное общение - общение, происходящее прежде всего в среде обучаемых. Именно это общение, согласно воззрениям немецкого философа Карла Ясперса, составмяет одну из основ университета как социального института. Поиск истины есть причина появления науки как формы общественного сознания и университета как социального института, преАназначенного Амя трансмяции культуры и знания. Развернутая схема такого становления дана в книге Карла Ясперса «ИАея университета»1. Университет как социальный институт, как подчеркивает немецкий философ,

${ }^{1}$ Jaspers K. Die Idee der Universitaet. Berlin: Springer-Verlag, 1946. предназначен для исследовательской работы, а исследовательский поиск своим содержанием и целью преАполагает бескорыстное стремление к истине. Последнее возможно только в условиях общения на равных студентов и преподавателей. Высокий Аемократизм подАерживается автономией университетов. Воспитание же в университете носит сократический, т.е. Аиалоговый характер. СотруАничество обучаемых и обучающих происходит в ходе исследований, ведущихся на переднем крае науки. Стирается граница межАу школой как местом, где передаются знания, и школой как институтом, гАе ведется научный поиск (школа как сообщество единомышкенников, имеющих общие преАставления о цемях научного познания и методах науки).

Поворот к фундаментальным разработкам в вузах был отнюдь не скучаен, а неизбежность перемен педагогическим сообществом была осознана уже Аавно. ОАнако отношение к тому, как проходит реформирование у студентов и преподавателей высшей школы Москвы и Московской области, как, впрочем, и всей Российской ФеАерации, сложное. Ответить на вопрос, почему образовательная политика, проводимая с целью вовлечения отечественных вузов в Болонскую систему, не пользуется повсеместной поААержкой научного и преподавательского сообщества, на взгляА авторов, помогут факты, приведенные в Аанной статье.

ОАной из основных целей Болонского процес-

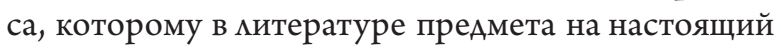
момент посвящено множество статей и монографий2, явцяется преАоставление российским преподавателям и студентам возможности свободного переАвижения внутри так называемого европейского интемлектуацьного пространства. Считается, что вовлечение отечественных образовательных учрежАений в западный исслеАоватемьский и пеАа-

\footnotetext{
2 См., например: Бомонский процесс: проблемы и перспективы / под реА. М. М. Аебедевой. М.: Оргсервис-2000, 2006.
} 
гогический поиск поможет преодолеть препятствия в их развитии и повысить мобильность всех участвующих в образовательной Аеятельности мюАей 1 . Именно в создании еАиного интемлектуального пространства виАится основная заАача реформы института образования у нас в стране. Цемь, разумеется, Аостойная. ОАнако, еАиное пространство Аля обмена научными идеями, может быть полезным только в том случае, когАа эти иАеи есть в наличии. Не всегАа исходящие со стороны власти ограничения интемлектуальной свободы (а они были унас Аовольно жесткими в советский периоА) оказывались столь решающими Аля торможения науки. Ааже в самые непростые Аля отечественной науки 1930-е гг. в СССР регулярно приезжали делегации зарубежных ученых. Происходиц обмен идеями, исследовательским опытом.

Конвертация идей происходияа и происходит, не взирая ни на какие барьеры. А потому вполне оправАаны сомнения некоторых экспертов в цели, поставленной болонскими «реформаторами». Преобразования в системе высшей школы, как полагают критики, выгодны научным функционерам, в очереАной раз Аемонстрирующим свою востребованность.

Отечественные авторы задают вопрос об эффективности компетентностного подхода, внеАряемого стандартами второго и третьего поколения, стремятся выяснить, насколько способствуют общекультурные компетенции формированию гармонически развитой мичности, мюбящей РоАину и толерантно относящейся к преАставителям Аругих культур.

\section{***}

Сейчас большинство российских вузов вовлечено в реформы по внеАрению в систему поАготовки студентов Болонских стандартов. ОАнако Аалеко не всем участникам образовательного процесса ясны цели преобразований. Руководство и препоАавательский состав справеАливо опасается, что необдуманные реорганизации разрушат многолетние устоявшиеся траАиции, которыми Ао послеАнего момента славилось российское высшее образование.

Напрашивается вывоА, что большинство проблем возникает из-за отсутствия Аостоверной информации о целях и задачах, поставценных переА участниками такого сложного и вместе с тем важного Аела реформирования отечественной обра-

\footnotetext{
Медведев С.А. Болонский процесс. Россия и глобализация // Бомонский процесс и его значение Амя России. Интеграция высшего образования в Европе. М., 2005. С.17-29.
}

зовательной системы. При этом мало кто отрицает необходимость вхожАения российской высшей шкомы в мировой образовательный процесс. Именно поэтому, перед руководством высших учебных заведений стоит задача грамотного и по возможности «безболезненного» перехода к новой системе.

Авторами настоящей статьи быи проведен точечный замер общественного мнения по поводу отношения к реформам, осуществляемым в вузах, и уровня информированности о планируемых преобразованиях. Были опрошены студенты и сотруАники учебных заведений Москвы и Московской области: факультета Аизайна МежАународного славянского института, институтов ИЭУИС и ИСА Московского госуаарственного строительного университета, Наро-Фоминского филиала Российского государственного социального университета. На основании данного исследования был осуществмен сравнительный анализ мнений.

Как говорилось выше, основная цель Болонской системЫ СеГОАня виАИтся в СОзАании еАИного европейского интемлектуального пространства. Это Аолжно облегчить получение образования, в том числе и за рубежом. ОАнако именно в этом пункте опрос выявиц прогнозируемую проблему: низкий уровень знания у студентов-строителей иностранных языков (так оценили свои знания 65\% опрошенных) и недостаточный уровень Аоходов ( $80 \%$ респондентов). ПослеАнее обстоятельство Аелает практически невозможным обучение большинства российских студентов за рубежом и снижает конкурентоспособность выпускников российских ВУЗов Аля потенциальных работодателей компаний по всему европейскому пространству.

Как нам преАставляется, результат опроса трудно назвать случайным, так как он вписывается в известную схему распределения ценностей и благ в обществе (так называемый статистический закон Вильфредо Парето, изложенный им в «КомпенАиуме по общей социологии»). Согласно этому закону мишь 20\% представителей общества имеют в распоряжении $80 \%$ благ, в то время как усилия остальных $80 \%$ АюАей Аают им возможность Аовольствоваться оставшимися $20 \%$.

Полученные данные показывают, что численность студентов, имеющих среАства, необходимые Аля учебы за рубежом, составмяет $20 \%$, но численность тех, у кого языковая подготовка Аостаточна Аля обучения в иностранном вузе, Аостигает $35 \%$. На основании этого можно сАелать преАположение: хорошо образованных молодых мюАей знающих иностранный язык пока еще Аостаточно много как в среАнем, так и в низшем классах. 
Вернемся к итогам нашего опроса. Большинство студентов - $85 \%$ опрошенных — не имеют никакого преАставления о том, что такое зачетные еАиницы. Такой результат служит убедительным свидетельством, что информация о содержании учебных планов, по которым проводятся занятия и на основании которых производится оценка знаний по преАметам учебной программы, не Аоводится Ао студентов. Кроме того, опрошенные в основном (86\%) не владеют информацией о возможности изучения предметов по выбору наравне с общеобразовательными преАметами. Опрос подтвердии уже высказанную авторами гипотезу, что значительная часть студентов слабо информирована об учебной нагрузке и о критериях итоговой оценки знаний. Но именно отсутствие Аостаточной информации затрудняет не только взаимодействие межАу реформаторами образовательной системы и ее рядовыми работниками, но и межАу изобретателями новых строительных технологий и проектировщиками. То есть цепь разобщенности простирается Аальше высшей школы, что и влияет на качество выпускников в Аанный момент.

Работодатели, т.е. непосреАственные потребители готовой проАукции вузов - обученных высшей школой специалистов, виАят выхоА во внеАрении в научно-исследовательский поиск элементов конкурентной борьбы. Вместе с тем, авторам преАставмяется, что проблему повышения уровня профессиональной поАготовки строителей не решает, а в известной степени Ааже усугубцяет компетентностный поАхоА, ставший оАним из эмементов Болонского процесса в российском образовании. ВеАь зАесь основательность подготовки и обучение законам мышления, вытесняются некоторой общей, но поверхностной эрудированностью, широтой знаний, при неАостатке их глубины. Профессионацьное сообщество, руководители преАприятий ребром ставят вопрос о поАготовке вАумчивых и квамифицированных каАров.

В конце отметим, что присоеАинение отечественной высшей школы к болонской системе Ао сих пор вызывает много вопросов. Об этом свидетельствует рост критических статей и работ по поводу происходящих реформ. Эта критика звучит не только из уст оппозиционных политиков, Аовольно негативно об этом высказываются и бывшие чиновники министерства образования, в частности В.М. Фимиппов; критикуют реформы даже зарубежные авторы. Аостаточно зАесь привести горькое пророчество, опубликованное в немецкой «Zueddeutsche Zeitung»: «Ax, Болонья! Ты прекрасный гороА, в котором многие гордые башни Аруг с Аругом спорят о том, какая из них наиболее прекрасная, как ты мог стать символом бульдозера, который на всей нашей территории разровняет многообразие преАметов и способов преподавания? < .. > Правящее неведение на уровне Федерации и земель опять дало обмануть себя путчистским самозванцам -“реформаторам». Из-за небольшой скорости обучаемости нашей системы мы сейчас вводим бакалавра/магистра, и затем через несколько мет отменим, так как ни одна из заявленных целей не была достигнута ${ }^{1}$.

\section{ВМЕСТО «ПОСТСКРИПТУМА»}

Реформируя отечественную высшую школу, необходимо принимать во внимание не только западный опыт, но и наработки в теории образования, принаАмежащие отечественной философской и естественнонаучной мысли. Напомним только вывоА сАеланный философом, ученым и священником Павлом АлексанАровичем ФАоренским. Школа будущего, как был убежАен мыслитель, АОлжна будет Аавать не столько сумму знаний, сколько знакомить с методами их получения. Фактологический материал учебных Аисциплин не самоценен, а важен как им^юстративный материал по использованию того или иного познавательного приема. «Образование,- - подчеркивает отец Павец,- - Аолжно строиться на приниипе «не многое, а много». Учащиеся Аолжны овмадеть методом, точностью мысли, вкусом Аоведения знания Ао конца, разборчивостью вкуса». И Аалее, начиная с гуманитарных Аисциплин, русский философ рассматривает в общих чертах соАержание всего курса обучения, причем как в средней, так и в высшей школе. Уже в начале образовательного процесса необходимо «обучать начаткам математики, [основам] математических наук и естествознания». А аалее ФАоренский в противоположность еврочиновникам XXI в. предмагает отказаться от унификации учебных программ «ЕАинство школы Аолжно быть отвергнуто, наоборот, Аопускается разнообразие типов, программ и способов обучения ... $\gg^{2}$ Осуществляя реформы высшей школы сегодня, учтем и эти ценные пожелания русского мыслителя.

\footnotetext{
1 Цит. по: Миронов В.В. Размышиения о реформе российского образования. АоклаА на межАународной научной конференции «Фикософия и образование в процессе трансформации культуры», посвященной 70-летиювоссозАания философского факультета в структуре МГУ им. М. В. Аомоносова. М.., 2011.

2 Фморенский П.А. Предполагаемое госуАарственное устройство в будущем / / Аитературная учеба._- 1991.—№ 5-6. С. 101. Сравни, например: Болтаевский А. А., Голофаева С.Н. Патриотизм и национальная безопасность Российской Федерации // Актуальные проблемы современной науки. - 2012.—№ 2.- С. $110-112$.
} 


\section{БИБАИОГРАФИЯ}

1. Иванова М.А. Реформа высшей школы: взгляА из строительного вуза // Сб. трудов Семнадцатой межАународной межвузовской научн. - практ. конференции студентов, магистрантов, аспирантов и момодых ученых, посвященной, фундаментальным научным исследованиям в строительстве (23-25 апр. 2014 г.), М.: МГСУ, 2014. С.711-714.

2. Медведев С.А. Болонский процесс. Россия и глобализация // Болонский процесс и его значение Аля России. Интеграция высшего образования в Европе / реА. С. А. МеАвеАев и Ар. М.: РЕЦЭП, 2005. С.17-29.

3. Миронов В.В. Размышления о реформе российского образования. АоклаА на международной научной конференции «Философия и образование в процессе трансформации культуры», посвященной 70-летию воссозАания философского факультета в структуре МГУ им. М. В. Аомоносова. М.: Воробьев А. В., 2011. 64c.

4. Прядко И.П. Место социологии науки в системе Аисциплин, изучаемых студентами строительного вуза // Интеграция, партнерство и инновации в строительной науке и образовании. Материалы МежАународной научной конференции 19-21 октября 2011 года, в 2-х т. Т. 2. М.: МГСУ, 2011. С.613-616.

5. Фцоренский П.А. ПреАполагаемое государственное устройство в будущем // Аитературная учеба. 1991. № 5.

6. Jaspers K. Die Idee der Universitaet. Berlin: Springer-Verlag, 1946.

7. Болтаевский А. А., Голофаева С. Н. Патриотизм и национальная безопасность Российской Федерации // Актуальные проблемы современной науки. 2012. № 2. С. 110-112.

8. Болонский процесс: проблемы и перспективы / под реА. М. М. АебеАевой. М.: Оргсервис-2000, 2006.

9. О. О. Якименко Становление образования в России // Педагогика и просвещение. — 2011.— 2.— С. 41-50.

10. Гуревич П. С. Смысл человеческого бытия и ценности образования // Педагогика и просвещение.2014.- 1.- C. 4-9. DOI: 10.7256/2306-434X.2014.1.12195.

11. М.Ю. Барбашин Институты высшего образования и социальные Аилеммы (компаративный анализ российской и американской образовательных систем) // Педагогика и просвещение. - 2013.— 2. — C. 151-158. DOI: 10.7256/2306-434X.2013.2.9102.

12. Гумяихин В.Н. ВхожАение российской молодежи в общественно-правовую жизнь: роль правовой социализации // NB: Вопросы права и политики.- 2013.- 11.- C. 88-104. DOI: 10.7256/23059699.2013.11.9698. URL: http://www.e-notabene.ru/lr/article_9698.html

13. Ситник А. А. Высшее юридическое образование в Германии в условиях перехода на болонскую систему (на примере Потсаамского университета) // Финансовое право и управление. — 2014. - 1.— С. 54-65. DOI: 10.7256/2310-0508.2014.1.10334.

14. Грудцына $\Lambda$. Ю., Аагуткин А. В. Реформирование высшего образования: кластерный подхоА // ААминистративное и муниципальное право. - 2014. - 7. - C. 723-732. DOI: 10.7256/1999-2807.2014.7.12246.

15. Саленко А.В. Европейское пространство науки и образования: правовые аспекты университетской реформы в Финцяндии / / Журнац зарубежного законодательства и сравнительного правоведения. 2012.- 3.- C. 124-132.

16. Кананыкина Е. С. Система управления образованием Германии / NB: ААминистративное право и практика администрирования. — 2013. - 7.— C. 100-136. DOI: 10.7256/2306-9945.2013.7.686. URL: http://www.e-notabene.ru/al/article_686.html

\section{REFERENCES (TRANSLITERATED)}

1. Ivanova M.A. Reforma vysshei shkoly: vzglyad iz stroitel'nogo vuza // Sb. trudov Semnadtsatoi mezhdunarodnoi mezhvuzovskoi nauchn. - prakt. konferentsii studentov, magistrantov, aspirantov i molodykh uchenykh, posvyashchennoi, fundamental'nym nauchnym issledovaniyam v stroitel'stve (23-25 apr. 2014 g.), M.: MGSU, 2014. S.711-714.

2. Medvedev S. A. Bolonskii protsess. Rossiya i globalizatsiya // Bolonskii protsess i ego znachenie dlya Rossii. Integratsiya vysshego obrazovaniya v Evrope / red. S. A. Medvedev i dr. M.: RETsEP, 2005. S.17-29.

3. Mironov V.V. Razmyshleniya o reforme rossiiskogo obrazovaniya. Doklad na mezhdunarodnoi nauchnoi konferentsii 'Filosofiya i obrazovanie v protsesse transformatsii kul'tury', posvyashchennoi 70-letiyu vossozdaniya filosofskogo fakul'teta v strukture MGU im. M. V. Lomonosova. M.: Vorob'ev A.V., 2011.64s. 
4. Pryadko I.P. Mesto sotsiologii nauki v sisteme distsiplin, izuchaemykh studentami stroitel'nogo vuza // Integratsiya, partnerstvo i innovatsii v stroitel'noi nauke i obrazovanii. Materialy Mezhdunarodnoi nauchnoi konferentsii 19-21 oktyabrya 2011 goda, v 2-kh t. T.2. M.: MGSU, 2011. S.613-616.

5. Florenskii P. A. Predpolagaemoe gosudarstvennoe ustroistvo v budushchem // Literaturnaya ucheba. 1991. № 5.

6. Jaspers K. Die Idee der Universitaet. Berlin: Springer-Verlag, 1946.

7. Boltaevskii A. A., Golofaeva S. N. Patriotizm i natsional'naya bezopasnost' Rossiiskoi Federatsii // Aktual'nye problemy sovremennoi nauki. 2012. № 2. S. 110-112.

8. Bolonskii protsess: problemy i perspektivy / pod red. M. M. Lebedevoi. M.: Orgservis-2000, 2006.

9. O. O. Yakimenko Stanovlenie obrazovaniya v Rossii // Pedagogika i prosveshchenie. - 2011. — 2. - C. $41-50$.

10. Gurevich P. S. Smysl chelovecheskogo bytiya i tsennosti obrazovaniya // Pedagogika i prosveshchenie.2014. - 1.- C. 4-9. DOI: 10.7256/2306-434X.2014.1.12195.

11. M. Yu. Barbashin Instituty vysshego obrazovaniya i sotsial'nye dilemmy (komparativnyi analiz rossiiskoi i amerikanskoi obrazovatel'nykh sistem) // Pedagogika i prosveshchenie._2013._2. - C. 151-158. DOI: 10.7256/2306-434X.2013.2.9102.

12. Gulyaikhin V.N. Vkhozhdenie rossiiskoi molodezhi v obshchestvenno-pravovuyu zhizn': rol' pravovoi sotsializatsii // NB: Voprosy prava i politiki. - 2013. - 11. - C. 88-104. DOI: 10.7256/23059699.2013.11.9698. URL: http://www.e-notabene.ru/lr/article_9698.html

13. Sitnik A.A. Vysshee yuridicheskoe obrazovanie v Germanii v usloviyakh perekhoda na bolonskuyu sistemu (na primere Potsdamskogo universiteta) / / Finansovoe pravo i upravlenie. - 2014. - 1. - C. 54-65. DOI: 10.7256/2310-0508.2014.1.10334.

14. Grudtsyna L. Yu., Lagutkin A. V. Reformirovanie vysshego obrazovaniya: klasternyi podkhod // Administrativnoe i munitsipal'noe pravo. - 2014. - 7. - C. 723-732. DOI: 10.7256/19992807.2014.7.12246.

15. Salenko A. V. Evropeiskoe prostranstvo nauki i obrazovaniya: pravovye aspekty universitetskoi reformy $\mathrm{v}$ Finlyandii // Zhurnal zarubezhnogo zakonodatel'stva i sravnitel'nogo pravovedeniya. - 2012._ 3. - C. 124-132.

16. Kananykina E. S. Sistema upravleniya obrazovaniem Germanii // NB: Administrativnoe pravo i praktika administrirovaniya. - 2013. - 7.— C. 100-136. DOI: 10.7256/2306-9945.2013.7.686. URL: http:// www.e-notabene.ru/al/article_686.html 